\title{
Una mirada a las producciones en Historia de la educación matemática en el VII Seminario Internacional de Investigación en Educación Matemática
}

\author{
Yohana Taise Hoffmann ${ }^{1}$ \\ yohana.thc@gmail.com \\ https://orcid.org/0000-0002-3590-315X \\ David Antonio da Costa ${ }^{1}$ \\ david.costa@ufsc.br \\ https://orcid.org/0000-0003-4493-9207 \\ Luiz Ricardo Nakamura ${ }^{1}$ \\ luiz.nakamura@ufsc.br \\ https://orcid.org/0000-0002-7312-2717 \\ ${ }^{1}$ Universidade Federal de Santa Catarina, Brasil
}

Recibido: 25/02/2020 Aceptado: 01/04/2020

\begin{abstract}
Resumen
Nuestro objetivo es analizar los trabajos presentados en el VII Seminario Internacional de Investigación en Educación Matemática (2018), pertenecientes al Grupo de Trabajo número 15 (GT15), Historia de la educación matemática. Tenemos la intención de responder las preguntas: ¿Cuáles son los grupos de investigación (GI's) presentes en el GT15? ¿Qué supuestos teóricos y metodológicos se utilizan? ¿Qué temas se están abordando? Utilizamos conceptos de Fleck y Bourdieu para abordar la producción, la constitución del campo científico y las relaciones entre el colectivo de investigadores. Con el software IRaMuTeQ presentamos una nube de palabras, además de aplicar el análisis factorial de correspondencia que ayuda a visualizar la proximidad y las distancias entre los trabajos presentados en el GT15, contribuyendo así a la identificación de temas comunes. Observamos que los GI's más presentes, dentro deste universo, son GHEMAT y GHOEM. La mayoría de los trabajos presentados provienen de instituciones de la región sureste, como UNESP y UNIFESP. Finalmente, utilizamos el software Gephi para construir una red de referencias compartidas, destacando la investigación que trata problemas en el campo científico de la Historia de la educación matemática, y sus diálogos con Historia, Filosofía y Sociología.
\end{abstract}

Palabras Clave: Campo científico, Gephi, grupos de investigación, IRaMuTeQ, SIPEM.

\section{Um olhar sobre as produções em História da educação matemática no VII Seminário Internacional de Pesquisa em Educação Matemática}

\begin{abstract}
Resumo
Nosso objetivo é analisar os trabalhos apresentados no VII Seminário Internacional de Pesquisa em Educação Matemática, em particular aqueles pertencentes ao Grupo de Trabalhos número 15 (GT15), intitulado História da educação matemática, realizado em 2018. Pretendemos responder aos seguintes questionamentos: Quais são os grupos de pesquisa (GP's) presentes no GT15? Quais pressupostos teóricos e metodológicos são mobilizados? Quais as temáticas que estão sendo tratadas? Utilizamos conceitos de Fleck e de Bourdieu para tratar a produção, a constituição do campo científico e as relações entre o coletivo de pesquisadores. Com o software
\end{abstract}


IRaMuTeQ apresentamos uma nuvem de palavras, além de aplicarmos a análise fatorial de correspondência que auxilia na visualização das proximidades e distanciamentos entre os trabalhos apresentados no GT15, contribuindo assim para a identificação de temáticas comuns. Observamos que os GP's mais presentes, dentro desse universo, são o GHEMAT e o GHOEM. A maioria dos trabalhos apresentados é oriunda de instituições da região sudeste, como UNESP e UNIFESP. Finalmente, utilizamos o software Gephi para construir uma rede de referências compartilhadas, evidenciando as pesquisas que tratam das problemáticas do campo científico da História da educação matemática, e seus diálogos com a História, Filosofia e Sociologia.

Palavras-chave: Campo científico, Gephi, grupos de pesquisa, IRaMuTeQ, SIPEM.

\title{
An Overview at the productions in the History of Mathematics Education at the VII International Research Seminar on Mathematics Education
}

\begin{abstract}
The main aim of this paper is to analyse the contributed papers presented at the VII International Research Seminar on Mathematics Education, in 2018, particularly those belonging to Working Group 15 (WG15) entitled History of Mathematics Education. We try to answer the following: Which are the research groups (RGs) present in the GT15? Which are the main theoretical and methodological approaches? What topics are being addressed? We used concepts by Fleck and Bourdieu to address the production and constitution of the scientific field and the relationship between the collective of researchers. Using IRaMuTeQ software we produce a word cloud and also apply a correspondence factor analysis that helps in visualising the proximity and distances among the contributed papers presented in WG15, thus contributing with the identification of common themes. We observed that the most present RGs are GHEMAT and GHOEM. Most presented papers come from institutions from the Southeastern region of Brazil, such as UNESP and UNIFESP. Finally, we use Gephi software in order to create a shared references network, highlighting researches addressing questions in the History of mathematics education scientific field, and its dialogues with History, Philosophy and Sociology.
\end{abstract}

Keywords: Scientific field, Gephi, research groups, IRaMuTeQ, SIPEM.

\section{Apresentação}

Para este artigo, temos como objetivo analisar os trabalhos apresentados no VII Seminário Internacional de Pesquisa em Educação Matemática (SIPEM), em particular aqueles pertencentes ao Grupo de Trabalhos (GT) número 15 (GT15), intitulado História da educação matemática, realizado no ano de 2018. Desta maneira, pretendemos responder aos seguintes questionamentos: Quais são os grupos de pesquisa presentes no GT15? Quais pressupostos teóricos e metodológicos são mobilizados nos trabalhos do GT15? Quais as temáticas que estão sendo tratadas pelos pesquisadores do GT15?

Destarte, é importante evidenciar os caminhos percorridos pelo coletivo de pesquisadores da História da educação matemática (Hem) até a conquista desse lugar no VII SIPEM. Segundo González (2018), a comunidade de pesquisadores interessados em estudar a 
Hem só vem aumentando. O autor elenca cinco aspectos que ilustram esse cenário, sendo o primeiro relacionado ao $13^{\text {th }}$ International Congress on Mathematical Education (ICME), realizado em Hamburgo (Alemanha) no ano de 2016:

1. Desenvolvimiento de grupos de trabajo estables en eventos de carácter internacional dedicados a la historia de la Educación Matemática, tales como el TSG 24 History of the teaching and learning of mathematics del International Congress of Mathematical Education, cuyos miembros comparten los hallazgos y asuntos pendientes en la historia de la educación matemática así como también trabajan en la búsqueda de acuerdos relacionados con las cuestiones metodológicas propias de la investigación en esta temática (González, 2018, p. 280, grifos do autor).

Outro aspecto importante foi o surgimento da revista International Journal on the History of Mathematics Education (IJHME), que circulou entre 2006 e 2016 (Furinghetti e Karp, 2018). A partir da movimentação dos pesquisadores em nível internacional, observou-se a necessidade de realizar um evento específico da Hem. No ano de 2009 foi realizada a primeira International Conference on the History of Mathematics Education (ICHME), tendo como sua edição mais recente a ICHME-6, ocorrida em 2019.

De acordo com González (2018), há mais quatro aspectos da comunidade de pesquisadores interessados em estudar a Hem:

2. Organización de eventos específicamente abocados al tema; entre estos destaca el Congreso Iberoamericano de Historia de la Educación Matemática, del cual se han llevado a efecto cuatro ediciones: I CIHEM 2011 (Covilhã, Portugal), II CIHEM 2013 (Cancún, México), III CIHEM 2015 (Belém do Pará, Brasil); VI CIHEM 2017 (Murcia, España); este CIHEM está considerado como un escenario que: propicia el intercambio académico, profesional y conceptual de los educadores matemáticos de América Latina, España y Portugal que tienen como asunto de interés investigativo a la historia de la educación matemática en estos espacios sociogeográficos; permite puestas en juego por dichos investigadores; coadyuva a la divulgación, difusión y publicación de la producción científica generada en este ámbito; promueve la creación de nuevos grupos de trabajo y la colaboración entre los que ya están creados; contribuye al examen del estado del arte en este emergente campo de estudio, así como también ayuda a configurar su prospectiva. 3. Apertura de Secciones Fijas en revistas propias del campo de la Educación Matemática; como ejemplo se puede mostrar la sección de la Revista UNIÓN intitulada Historia Social de la Educación Matemática en Iberoamérica (ver: http://www.fisem.org/www/union/) 
4. Creación de Revistas Especializadas como HISTEMAT - Revista de História da Educação (http://histemat.com.br/index.php/HISTEMAT) enfocada en la divulgación, entre investigadores, profesores, y demás personas interesadas en la dimensión histórica tanto de la matemática como de su enseñanza, de resultados de investigaciones relativas a la historia de la educación matemática y otros asuntos conexos.

5. Publicación de Handbook, como el Handbook on the History of Mathematics Education (KARP, SCHUBRING, 2014) en el cual se examina la historia de la educación matemática considerando múltiples épocas, civilizaciones, países y culturas; teniendo presente el interés que un número cada vez mayor de educadores matemáticos en todo el mundo, tiene sobre el desarrollo disciplinario de la Educación Matemática, no sólo en sus países de origen, sino a nivel global (González, 2018, p. 280-281, grifos do autor).

Segundo Matos e Saraiva (2011), o CIHEM teve como interesse o intercâmbio "entre pesquisadores e a produção de conhecimento ligada à história da educação matemática na América Latina, na Espanha e em Portugal. O interesse pela temática tem crescido enormemente no âmbito da Educação Matemática nesses diversos países” (p. 07). A quinta edição do CIHEM ocorreu no ano de 2019 (Bogotá, Colômbia).

A partir da participação no I CIHEM, vários pesquisadores brasileiros observaram a necessidade da criação de um evento em âmbito nacional. No ano de 2012 realizou-se o primeiro Encontro Nacional de Pesquisa em História da Educação Matemática (ENAPHEM), no município de Vitória da Conquista, Bahia (Brasil). O V ENAPHEM, diferente das últimas edições, será virtual, diante da Pandemia COVID-19, e tem previsão para novembro de 2020, a realização do evento conta com o apoio da UFRN.

Dessa forma, cabe destacar como mais um espaço para a socialização das pesquisas que investigam a Hem, o Seminário Internacional de Pesquisa em Educação Matemática (SIPEM). Segundo Coppe et al. (2018), os primeiros trabalhos apresentados no âmbito da Hem no SIPEM, datam do II SIPEM, realizado no ano de 2003, com quatro pesquisas aprovadas, alocadas no GT 5 - História da Matemática e Cultura.

No ano de 2018 ocorreu o VII SIPEM, inaugurando o GT15, intitulado História da educação matemática. Segundo os coordenadores do GT15, Maria Cristina Araújo de Oliveira e Antonio Vicente Marafioti Garnica, a iniciativa para a criação do mesmo ocorreu no ano de 
2016 em reunião na Sociedade Brasileira de Educação Matemática $\left(\right.$ SBEM) ${ }^{1}$ (Oliveira e Garnica, 2018).

A participação de diversos grupos de pesquisa nesses eventos contribui "para a escrita da história da educação matemática e que a partir de diferentes afiliações teóricas e para além da disputa de status acadêmico, deram visibilidade à pluralidade historiográfica do evento, a uma produção de histórias singulares" (Pinto, 2014, p. 16-17). Assim, os eventos são espaços significativos para a divulgação e socialização da produção do conhecimento no campo científico.

Segundo Bourdieu (2001a), o campo científico é um espaço social constituído por relações de força e de dominação, no qual os agentes estão dispostos de acordo com sua posição, isto é, entre dominantes ou dominados, sendo "microcosmos que, sob certos aspectos, constituem mundos sociais idênticos aos demais, com concentrações de poder e de capital, monopólios, relações de força, interesses egoístas, conflitos etc.” (p. 133). Dessa maneira, a conquista de novos espaços legitima o próprio campo que está em processo de constituição, institucionalização e disciplinarização.

\section{Conquista de novos espaços: VII Seminário Internacional de Pesquisa em Educação Matemática}

Como mencionamos anteriormente, os eventos são espaços importantes e contribuem para a legitimação do campo científico, além da socialização e divulgação de suas produções. Logo, a conquista de novos espaços e lugares para debates são necessários para o reconhecimento desse campo que está se constituindo. Apresentamos neste trabalho uma nova possibilidade para as discussões das pesquisas que investigam a Hem, o VII SIPEM, em particular o GT15, realizado entre os dias 4 e 8 de novembro de 2018, na cidade de Foz do Iguaçu, no estado do Paraná (Brasil).

A proposição do GT15 reuniu pesquisadores que atuam na Hem pertencentes a diversos Grupos de Pesquisas (GP's). Organizados de forma cronológica de criação, são eles (Oliveira e Garnica, 2018, p. 155):

\footnotetext{
${ }^{1}$ Destacamos o artigo de Miguel et al. (2004), referentes a configuração do campo da Educação Matemática no Brasil, que realizou um panorama histórico, expõe e analisa como esse campo foi se consolidando, assim como, a importância da SBEM e dos eventos da área.
} 
- História, Filosofia e Educação Matemática (HIFEM)², a partir de meados de 1996 se organizou autonomamente como um grupo de pesquisa, possui atualmente como líderes Arlete de Jesus Brito e Andreia Dalcin, alocado na Universidade Estadual Paulista Júlio de Mesquita Filho (UNESP);

- Grupo de Pesquisa em História da Educação Matemática no Brasil (GHEMAT) ${ }^{3}$ instituído no ano 2000, pelos líderes Wagner Rodrigues Valente e Neuza Bertoni Pinto, na Universidade Federal de São Paulo (UNIFESP);

- Grupo de Pesquisa História Oral e Educação Matemática (GHOEM) ${ }^{4}$, possui como líderes Antonio Vicente Marafioti Garnica e Heloisa da Silva, criado no ano de 2002, na Universidade Estadual Paulista Júlio de Mesquita Filho (UNESP);

- Grupo Compasso $(D F)^{5}$, originou-se do Grupo de Estudo e Pesquisa em Educação Matemática (GEPEM-DF). Em 2006 o GEPEM-DF reviu seus objetivos e a partir de uma consulta aos seus membros, passou a denominar-se COMPASSODF. Atualmente é um grupo não institucional composto pelas pesquisadoras: Carmyra Oliveira Batista (SEEDF), Edilene Simões Costa (UFMS), Mônica Menezes de Souza (SEEDF), Rosália Policarpo Fagundes (SEEDF);

- Grupo de Estudos Contemporâneos em Educação Matemática (GECEM) ${ }^{6}$, criado no ano de 2009 na Universidade Federal de Santa Catarina (UFSC), tendo como líderes Cláudia Regina Flores e Rosilene Beatriz Machado;

- História da Educação Matemática em Pesquisa $(H E M E P)^{7}$, criado no ano de 2011, na Universidade Federal de Mato Grosso do Sul (UFMS), possui como líderes Luzia Aparecida de Souza e Thiago Pedro Pinto;

- Grupo Potiguar de Estudos e Pesquisas em História da Educação Matemática $(G P E P)^{8}$, da Universidade Federal do Rio Grande do Norte (UFRN), possui como líderes Liliane dos Santos Gutierre e Fernando Guedes Cury, instituído no ano de 2013.

De acordo com informações na página da SBEM a respeito da criação do SIPEM, o evento é uma das atividades mais importantes da sociedade, ao possibilitar a abrangência e divulgação das produções das pesquisas em educação matemática ${ }^{9}$. Apresentamos um breve

2 Disponível em: 〈http://dgp.cnpq.br/dgp/espelhogrupo/200458>. Acesso em: 06 mai. 2019.

${ }^{3}$ Disponível em: 〈http://dgp.cnpq.br/dgp/espelhogrupo/11665> Acesso em: 06 mai. 2019.

${ }^{4}$ Disponível em: 〈http://dgp.cnpq.br/dgp/espelhogrupo/4544>. Acesso em: 06 mai. 2019.

${ }^{5}$ Disponível em: 〈http://www.compassodf.com.br/>. Acesso em: 06 mai. 2019.

${ }^{6}$ Disponível em: 〈http://dgp.cnpq.br/dgp/espelhogrupo/4673〉 Acesso em: 06 mai. 2019.

${ }^{7}$ Disponível em: <http://dgp.cnpq.br/dgp/espelhogrupo/18311>. Acesso em: 06 mai. 2019.

${ }^{8}$ Disponível em: 〈http://dgp.cnpq.br/dgp/espelhogrupo/38904〉. Acesso em: 06 mai. 2019.

9 Para mais informações disponível em: <http://www.sbem.com.br/sbembrasil/index.php/grupo-detrabalho/historico-sipem>. Acesso em: 09 mai. 2019. 
panorama das edições do SIPEM, a fim de situar histórico e socialmente o lugar de fala desses pesquisadores.

O primeiro SIPEM $^{10}$ ocorreu após a discussão de diversos GP's que investigam a Educação Matemática, provenientes diferentes instituições do ensino superior no Brasil, que reconheceram a necessidade de se realizar um intercâmbio com pesquisadores e grupos de outros países, para além de avaliar a produção, realizar parcerias em projetos e grupos de estudos e pesquisas, em nível nacional e internacional.

O I SIPEM foi realizado entre os dias 22 e 25 de novembro de 2000, na cidade de Serra Negra, São Paulo (Brasil), tendo como tema a Investigação em Educação Matemática no Brasil, em que se destacam as seguintes palestras com convidados de renome nacional e internacional nas pesquisas em Educação Matemática: A investigação sobre o professor de Matemática: problemas e perspectivas, com a participação do professor João Pedro da Ponte; O conceito da multiplicação: um obstáculo epistemológico, palestra proferida pelo professor Gert Schubring; O que a ciência cognitiva corpórea pode dizer sobre a natureza humana da matemática, realizada pelo professor Rafael Nuñez; e Desafios da Educação Matemática no ano 2000, pelo professor Ubiratan D’Ambrosio (Campos e Pires, 2000).

O evento contou com dez grupos de trabalhos. A saber, GT1: Educação Matemática nas séries iniciais do EF; GT2: Educação Matemática nas séries finais do EF; GT3: Educação Matemática no Ensino Médio; GT4: Educação Matemática no Ensino Superior; GT5: História da Matemática e Cultura; GT6: Educação Matemática: Novas Tecnologias e Ensino a Distância; GT7: Formação de Professores que ensinam Matemática; GT8: Avaliação em Educação Matemática; GT9: Processos Cognitivos e Linguísticos na Educação Matemática; GT10: Modelagem Matemática (este último GT não consta nos Anais do evento) (Campos e Pires, 2000).

No ano de 2003, entre os dias 29 de outubro e 01 de novembro, foi realizado o II SIPEM $^{11}$, na cidade de Santos, São Paulo (Brasil). O evento teve a inclusão de mais dois GTs, a saber, GT11: Filosofia da Educação Matemática e GT12: Ensino de probabilidade e estatística. A temática do evento estava alinhada com a realização do I Fórum Nacional das Licenciaturas,

\footnotetext{
${ }^{10}$ Para mais informações disponível em: 〈http://www.sbembrasil.org.br/files/sipemI.pdf $>$. Acesso em: 09 mai. 2019.

${ }^{11}$ Para mais informações disponível em: 〈http://www.sbembrasil.org.br/files/sipemII.pdf $>$. Acesso em: 09 mai. 2019.
} 
em São Paulo, e com o Seminário Nacional das Licenciatura, em Salvador. Assim, o tema foi $A$ contribuição das pesquisas para a formação de professores de Matemática (Valente, 2013).

O III SIPEM ${ }^{12}$ foi realizado entre os dias 10 e 14 de outubro de 2006, na cidade de Águas de Lindóia, São Paulo (Brasil). Uma importante observação a ser feita é que os Anais do evento estão com páginas faltantes, iniciando com uma errata em relação a um trabalho do GT1, em seguida trazendo um trabalho do GT5 e, nas páginas subsequentes, não há como distinguir se são trabalhos do GT5 ou de outro GT, sendo difícil identificar os trabalhos de cada GT (Garnica et al., 2006). No ano de 2009, entre os dias 25 e 28 de outubro em Brasília, no Distrito Federal (Brasil), foi realizado o IV SIPEM, e o que tem-se é o relatório e anais do evento ${ }^{13}$. Ao todo foram 244 trabalhos inscritos, sendo 198 aprovados e, destes, 162 trabalhos apresentados (Santos e Lima, 2009).

Em Petrópolis, no estado do Rio de Janeiro (Brasil), entre os dias 28 e 31 de outubro de 2012, foi realizado o V SIPEM ${ }^{14}$. Segundo a apresentação dos anais, a SBEM possuía cerca de 15.000 associados em todo país, e já havia realizado dez Encontros Nacionais de Educação Matemática (ENEM), além de inúmeros encontros regionais. O evento contou com 313 pesquisadores inscritos e com 154 apresentações e discussões de trabalhos (Bellemain e Gitirana, 2012).

O VI SIPEM ${ }^{15}$ foi realizado no ano de 2015, entre os dias 15 e 19 de novembro, na cidade de Pirenópolis, Goiás (Brasil), contando com a participação de 319 pesquisadores inscritos e com a apresentação e discussão de 169 trabalhos de investigação científica, além de um novo GT (GT13: Diferença, Inclusão e Educação Matemática) (Fernandes, 2015).

A última edição do evento até o momento, o VII SIPEM ${ }^{16}$, foi realizado entre os dias 4 e 8 de novembro de 2018, na cidade de Foz do Iguaçu (PR), contando com a implementação de

\footnotetext{
12 Para mais informações disponível em: 〈http://www.sbembrasil.org.br/files/sipemIII.pdf>. Acesso em: 09 mai. 2019.

${ }^{13}$ Para mais informações disponível em:

<http://www.sbembrasil.org.br/sbembrasil/images/Relatrio\%20Geral\%20do\%20IV\%20SIPEM.pdf > e <http://www.sbembrasil.org.br/files/sipemIV.pdf>. Acesso em: 09 mai. 2019.

${ }^{14}$ Para mais informações disponível em: 〈http://www.sbembrasil.org.br/sbembrasil/images/Boletim\%2019.pdf> e <http://www.sbembrasil.org.br/files/v_sipem/?page=presentation\&language=br > . Acesso em: 09 mai. 2019.

15 Para mais informações disponível em: <http://www.sbembrasil.org.br/sbembrasil/images/arquivos/relatorio_visipem.pdf $>$ e <http://www.sbembrasil.org.br/visipem/anais/story_html5.html>. Acesso em: 09 mai. 2019.

${ }^{16}$ Para mais informações disponível em: 〈http://www.sbembrasil.org.br/files/relatorio_viisipem.pdf $>$ e <http://www.sbemparana.com.br/viisipem/portuguese/index.php>. Acesso em: 09 mai. 2019.
} 
mais dois GTs, a saber GT14: Didática da Matemática e GT15: História da Educação Matemática. Estiveram presentes 365 pesquisadores inscritos no evento, todos sócios da SBEM, com um total de 226 trabalhos aceitos para apresentação e publicação, e seis aceitos somente para publicação. De acordo com os coordenadores do GT15 alguns trabalhos foram selecionados para uma edição temática na Revista HISTEMAT ${ }^{17}$ (Carneiro, 2018).

Cabe destacar que há diversos artigos que realizaram análises dos trabalhos apresentados no SIPEM durante esses anos, a exemplo de Mocrosky, Paulo e Bicudo (2010) e Bicudo e Paulo (2011) que analisaram os trabalhos apresentados no III SIPEM, investigando as tendências das pesquisas em Educação Matemática no Brasil. Assim como, as pesquisas referentes à temática da Modelagem Matemática, como, Bicudo e Kluber (2011) e Kluber e Burak (2012) que analisaram os anais do III SIPEM, Kluber e Burak (2014) que utilizaram os trabalhos do IV SIPEM, em específico o GT10, e Oliveira e Kluber (2017) que analisaram quatro edições do SIPEM (2006, 2009, 2012 e 2015), a partir dos relatórios do GT10. Podemos destacar o trabalho de Bicudo e Miarka (2015) relacionado a metodologia de pesquisa em Filosofia da Educação Matemática, analisando os trabalhos do V SIPEM. Outro tema de investigação é o trabalho de Dos Anjos e Moretti (2017) relacionado ao ensino e aprendizagem em matemática para estudantes cegos, em que os autores realizaram um levantamento a respeito da educação inclusiva em diversos eventos, e nos anais do SIPEM encontraram trabalhos nos anos 2003, 2006, 2009, 2012 e 2015.

Dado o histórico do SIPEM, constituir um espaço de discussões em um determinado campo científico possui um capital simbólico, ou seja, segundo Bourdieu (2001a), são manifestações de reconhecimento social, "nos livra da insignificância, como ausência de importância e de sentido” (p. 296). Assim como configura-se um capital científico na área da Hem, isto é, de acordo com Bourdieu (2001b):

O capital científico funciona como um capital simbólico de reconhecimento que vale, antes de mais, e por vezes exclusivamente, nos limites do campo (embora possa ser reconvertido noutras espécies de capital, principalmente econômico): o peso simbólico de um cientista tende a variar segundo o valor distintivo dos seus contributos e a originalidade que os pares concorrentes reconhecem ao seu contributo distintivo (p. 80, grifo do autor).

\footnotetext{
${ }^{17}$ Para maiores informações disponível em: 〈http://www.histemat.com.br/index.php/HISTEMAT/issue/view/13 >. Acesso em 06 mai. 2019.
} 
Esse novo espaço adquirido é significativo para compreender a representatividade e legitimidade desse coletivo de pesquisadores na Hem. Dessa maneira, como mencionado na seção de apresentação, pretendemos analisar os trabalhos que foram apresentados no GT15. A fim de responder alguns questionamentos, como, por exemplo, quais são os grupos de pesquisa presentes no GT15? Quais pressupostos teóricos e metodológicos são mobilizados nos trabalhos do GT15? Quais as temáticas que estão sendo tratadas pelos pesquisadores do GT15?

\section{Corpus de análise: trabalhos apresentados no GT15 do VII SIPEM}

O corpus de análise é composto pelos trabalhos aprovados no GT15 do VII SIPEM. Em um primeiro momento foram submetidos 20 trabalhos e, após a avaliação dos pareceristas, foram publicados um total de 17 textos (Quadro 1).

Quadro 1 - Trabalhos aprovados no GT15 - VII SIPEM.

\begin{tabular}{|c|c|c|c|c|}
\hline ID & Título do Trabalho & Autores & Instituição & GP \\
\hline \multirow[b]{2}{*}{$\mathrm{T} 1$} & \multirow{2}{*}{$\begin{array}{c}\text { Uma proposta do uso da história da matemática } \\
\text { na formação continuada de professores, uma } \\
\text { experiência com professores do interior do estado } \\
\text { de São Paulo }\end{array}$} & Adriana de Bortoli & FATEC-SP & HIFEM \\
\hline & & $\begin{array}{l}\text { Zionice Garbelini } \\
\text { Martos Rodrigues }\end{array}$ & IFSP & HIFEM \\
\hline \multirow{2}{*}{$\mathrm{T} 2$} & \multirow{2}{*}{$\begin{array}{c}\text { Formação de professores de matemática de MT e } \\
\text { MS: indícios de um projeto global de } \\
\text { colonialidade de poder }\end{array}$} & $\begin{array}{l}\text { Ana Maria de } \\
\text { Almeida }\end{array}$ & UFMS & GHOEM \\
\hline & & $\begin{array}{c}\text { Luzia Aparecida de } \\
\text { Souza }\end{array}$ & UFMS & GHOEM \\
\hline $\mathrm{T} 3$ & $\begin{array}{l}\text { O desenho na Reforma João Pinheiro de } 1906 \text { em } \\
\text { Minas Gerais }\end{array}$ & $\begin{array}{l}\text { Andréia Magalhães } \\
\text { Dias Almeida }\end{array}$ & UFJF & GHEMAT \\
\hline $\mathrm{T} 4$ & $\begin{array}{c}\text { Grupo de pesquisa história oral e educação } \\
\text { matemática: mapeamento da formação e atuação } \\
\text { de professores que ensinam/ensinaram } \\
\text { matemática no Brasil }\end{array}$ & $\begin{array}{l}\text { Antonio Vicente } \\
\text { Marafioti Garnica }\end{array}$ & UNESP & GHOEM \\
\hline \multirow{2}{*}{$\mathrm{T} 5$} & \multirow{2}{*}{$\begin{array}{l}\text { Trabalho manual e geometria no curso primário } \\
\text { do Distrito Federal (final do século XIX) }\end{array}$} & $\begin{array}{l}\text { Claudia Regina } \\
\text { Boen Frizzarini }\end{array}$ & UNIFESP & GHEMAT \\
\hline & & $\begin{array}{l}\text { Maria Célia Leme da } \\
\text { Silva }\end{array}$ & UNIFESP & GHEMAT \\
\hline \multirow{2}{*}{ T6 } & \multirow{2}{*}{$\begin{array}{l}\text { Rizza de Araújo Porto: uma expert em tempos da } \\
\text { escola nova? }\end{array}$} & $\begin{array}{l}\text { Denise Medina } \\
\text { França }\end{array}$ & UERJ & GHEMAT \\
\hline & & $\begin{array}{l}\text { Edilene Simões } \\
\text { Costa Santos }\end{array}$ & UFMS & GHEMAT \\
\hline $\mathrm{T} 7$ & $\begin{array}{c}\text { Monumentos arquitetônicos: uma fonte de } \\
\text { pesquisa em história da educação matemática }\end{array}$ & $\begin{array}{l}\text { Elmha Coelho } \\
\text { Martins Moura }\end{array}$ & UNILA & HIFEM \\
\hline $\mathrm{T} 8$ & $\begin{array}{l}\text { Grupo de pesquisa História Oral e Educação } \\
\text { Matemática: dos estudos sobre intervenções na } \\
\text { formação de professores }\end{array}$ & Heloisa da Silva & UNESP & GHOEM \\
\hline T9 & $\begin{array}{l}\text { Grupo de Pesquisa História Oral e Educação } \\
\text { Matemática: dos estudos sobre História da } \\
\text { Educação Matemática (Inclusiva) }\end{array}$ & Ivete Maria Baraldi & UNESP & GHOEM \\
\hline
\end{tabular}


Quadro 1 - Trabalhos aprovados no GT15 - VII SIPEM (continuação)

\begin{tabular}{|c|c|c|c|c|}
\hline \multirow[b]{2}{*}{$\mathrm{T} 10$} & \multirow[b]{2}{*}{$\begin{array}{l}\text { História oral, identidade e a constituição de um } \\
\text { currículo }\end{array}$} & Jardel da Silva Costa & UFRJ & Sem GP \\
\hline & & $\begin{array}{l}\text { Márcia Maria Fusaro } \\
\text { Pinto }\end{array}$ & UFRJ & CHATER $^{18}$ \\
\hline \multirow[b]{2}{*}{ T11 } & \multirow{2}{*}{$\begin{array}{l}\text { Uma história da educação financeira na educação } \\
\text { básica escolar: uma análise de livros didáticos }\end{array}$} & $\begin{array}{l}\text { Jéssica Ignácio de } \\
\text { Souza }\end{array}$ & UFSC & GECEM \\
\hline & & $\begin{array}{l}\text { Cláudia Regina } \\
\text { Flores }\end{array}$ & UFSC & GECEM \\
\hline \multirow{2}{*}{$\mathrm{T} 12$} & \multirow{2}{*}{$\begin{array}{l}\text { Resolução de problemas pelas equações } \\
\text { algébricas: a proposta de Tito Cardoso de } \\
\text { Oliveira para o ensino das operações }\end{array}$} & $\begin{array}{l}\text { Luciane de Fatima } \\
\text { Bertini }\end{array}$ & UNIFESP & GHEMAT \\
\hline & & $\begin{array}{c}\text { Ivone Lemos da } \\
\text { Rocha } \\
\end{array}$ & UNIFESP & GHEMAT \\
\hline $\mathrm{T} 13$ & $\begin{array}{l}\text { O desenho e a profissionalidade dos professores } \\
\text { primários no século XIX }\end{array}$ & $\begin{array}{c}\text { Maria Cristina } \\
\text { Araújo de Oliveira }\end{array}$ & UFJF & GHEMAT \\
\hline T14 & $\begin{array}{l}\text { Grupo de pesquisa história oral e educação } \\
\text { matemática: dos estudos sobre hermenêutica de } \\
\text { profundidade }\end{array}$ & $\begin{array}{l}\text { Maria Edneia } \\
\text { Martins-Salandim }\end{array}$ & UNESP & GHOEM \\
\hline T15 & 75 anos de história do ensino médio no Brasil & $\begin{array}{l}\text { Martha Regina Egéa } \\
\text { Kleine }\end{array}$ & SEE-SP & HIFOPEM $^{19}$ \\
\hline T16 & $\begin{array}{c}\text { A geometria e o Movimento da Matemática } \\
\text { Moderna em Minas Gerais: referências e práticas } \\
\text { de uma professora de Juiz de Fora }\end{array}$ & $\begin{array}{l}\text { Thiago Neves } \\
\text { Mendonça }\end{array}$ & IFMG & GHEMAT \\
\hline \multirow{2}{*}{$\mathrm{T} 17$} & \multirow{2}{*}{$\begin{array}{l}\text { Uma genealogia na história da educação } \\
\text { matemática do Rio Grande do Norte }\end{array}$} & $\begin{array}{l}\text { Wguineuma Pereira } \\
\text { Avelino Cardoso }\end{array}$ & IFESP & HIFEM \\
\hline & & $\begin{array}{c}\text { Liliane dos Santos } \\
\text { Gutierre }\end{array}$ & UFRN & HIFEM \\
\hline
\end{tabular}

Fonte: Dados da Pesquisa

A partir do Quadro 1, podemos identificar autores de distintas instituições de ensino superior e grupos de pesquisas, assim como, podemos analisar quais os pressupostos teóricos e metodológicos que são mobilizados e quais as temáticas que estão sendo tratadas no GT15.

O Gráfico1 apresenta as instituições em que cada autor está vinculado, sendo possível observar que aquelas com mais pesquisadores que apresentaram trabalhos foram a Universidade Estadual Paulista Júlio de Mesquita Filho (UNESP) e Universidade Federal de São Paulo (UNIFESP) (16\% do total cada instituição) correspondendo a quatro pesquisadores cada. Em seguida, a Universidade Federal de Mato Grosso do Sul (UFMS) com 12\%, com três pesquisadores. Correspondendo a $8 \%$, com dois pesquisadores cada instituição, salientando que são trabalhos em coautorias, estão a Universidade Federal de Juiz de Fora (UFJF), Universidade Federal do Rio de Janeiro (UFRJ) e a Universidade Federal de Santa Catarina (UFSC).

\footnotetext{
18 Grupo de pesquisa Teoria da Histórico-cultural da Atividade na pesquisa em Educação (CHATER). Para maiores informações disponível em: 〈http://dgp.cnpq.br/dgp/espelhogrupo/12838>. Acesso em 06 mai. 2019.

${ }^{19}$ Grupo de pesquisa Histórias de Formação de Professores que ensinam Matemática (HIFOPEM). Para maiores informações disponível em: 〈http://dgp.cnpq.br/dgp/espelhogrupo/34587>. Acesso em 06 mai. 2019.
} 


\section{Gráfico 1 - GT15, número de autores por IES no VII SIPEM.}

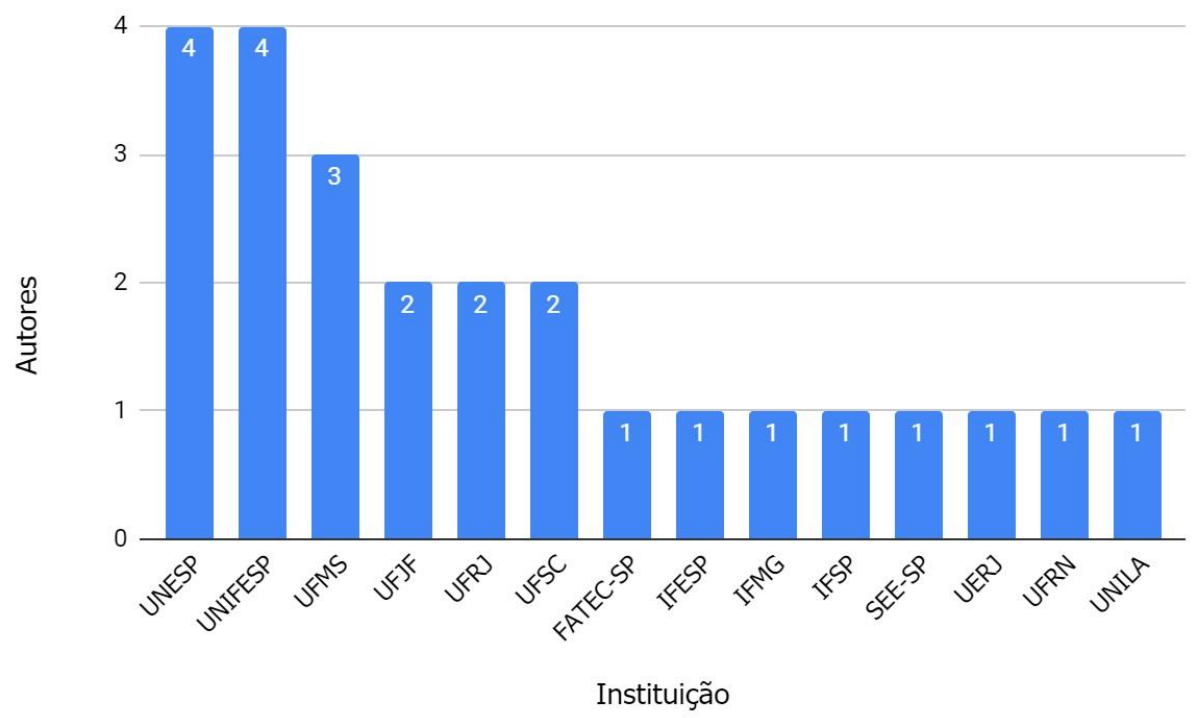

Fonte: Dados da Pesquisa

Em relação aos GP's, identificamos seis principais (Gráfico 2). No entanto, cabe ressaltar que há autores dos trabalhos que participam de mais de um GP. Há casos, por exemplo, em que o autor do trabalho é estudante no GHOEM e no HEMEP, como também é estudante no HIFEM e no GPEP. Outros exemplos são os/as pesquisadores(as) que participam do HIFEM e é líder do GPEP, o mesmo acontece com um pesquisador do GHOEM e líder do HEMEP.

Gráfico 2 - GT15, número de autores por GPs no VII SIPEM.

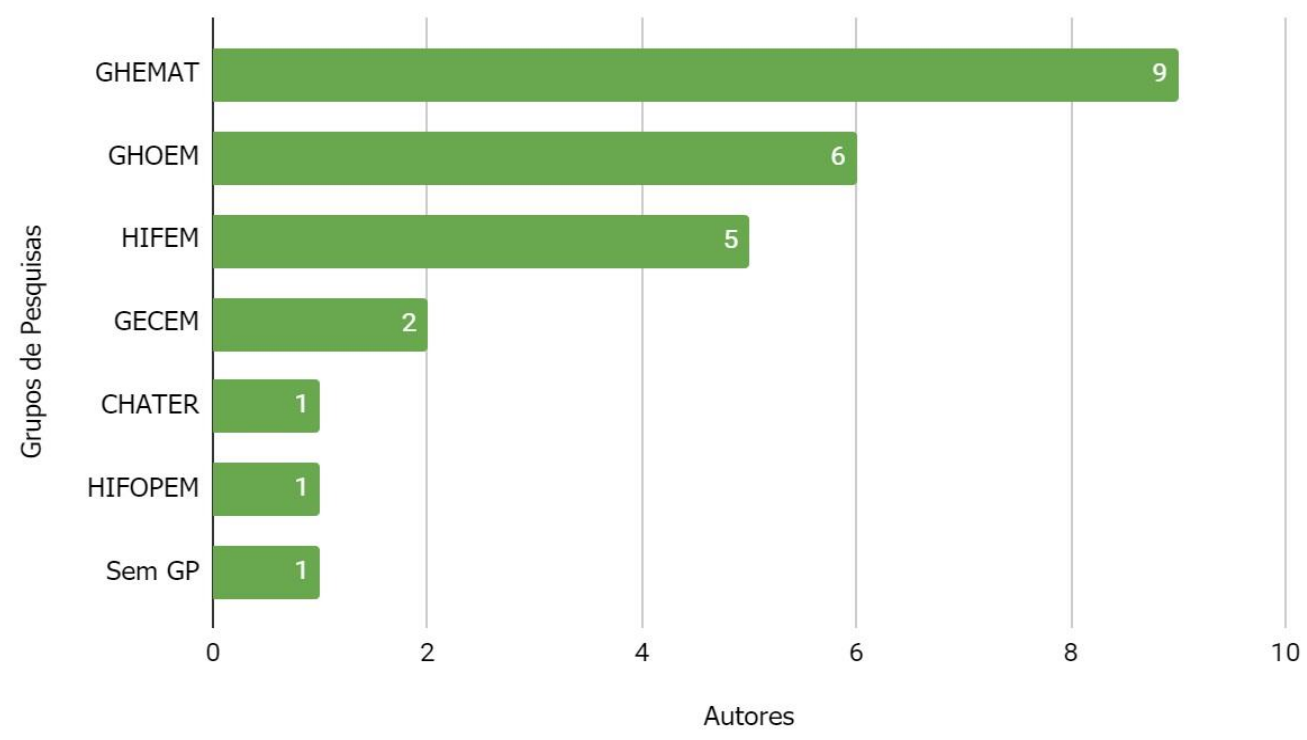

Fonte: Dados da Pesquisa 
A partir do Gráfico 2, podemos observar que o GP que mais teve representantes presentes no VII SIPEM foi o GHEMAT, com nove autores, totalizando 36\%, que correspondem a seis trabalhos apresentados, a saber: T3, T5, T6, T12, T13 e T16. Em seguida está o GHOEM, com $24 \%$, tendo seis autores e cinco trabalhos, sendo eles: T2, T4, T8, T9 e T14. O terceiro grupo com mais representantes é o HIFEM, correspondendo a $20 \%$ do total, com cinco autores e três trabalhos apresentados, T1, T7 e T17.

Outra informação que obtemos para compreender o lugar das produções desse campo, são as titulações desses pesquisadores, conforme apresentado no Gráfico 3. Esse dado é importante para identificarmos a especialização desses pesquisadores que investigam a Hem. Quais são os lugares de fala, suas influências teóricas e metodológicas? Observamos (Gráfico 3) que a maioria dos participantes no GT15 do VII SIPEM possuem doutorado em Educação Matemática, correspondendo a $36 \%$ do total, ou nove pesquisadores. Em seguida, temos os pesquisadores que possuem doutorado em Educação, correspondendo a 32\%, isto é, oito pesquisadores. Os $32 \%$ restantes correspondem a mestrandos e doutorandos dos seguintes programas de pós-graduação: Educação matemática; Educação científica e tecnológica; Ensino e história da matemática e da física; e em Educação e saúde na infância e adolescência.

Gráfico 3- GT15, número de autores por titulação no VII SIPEM.

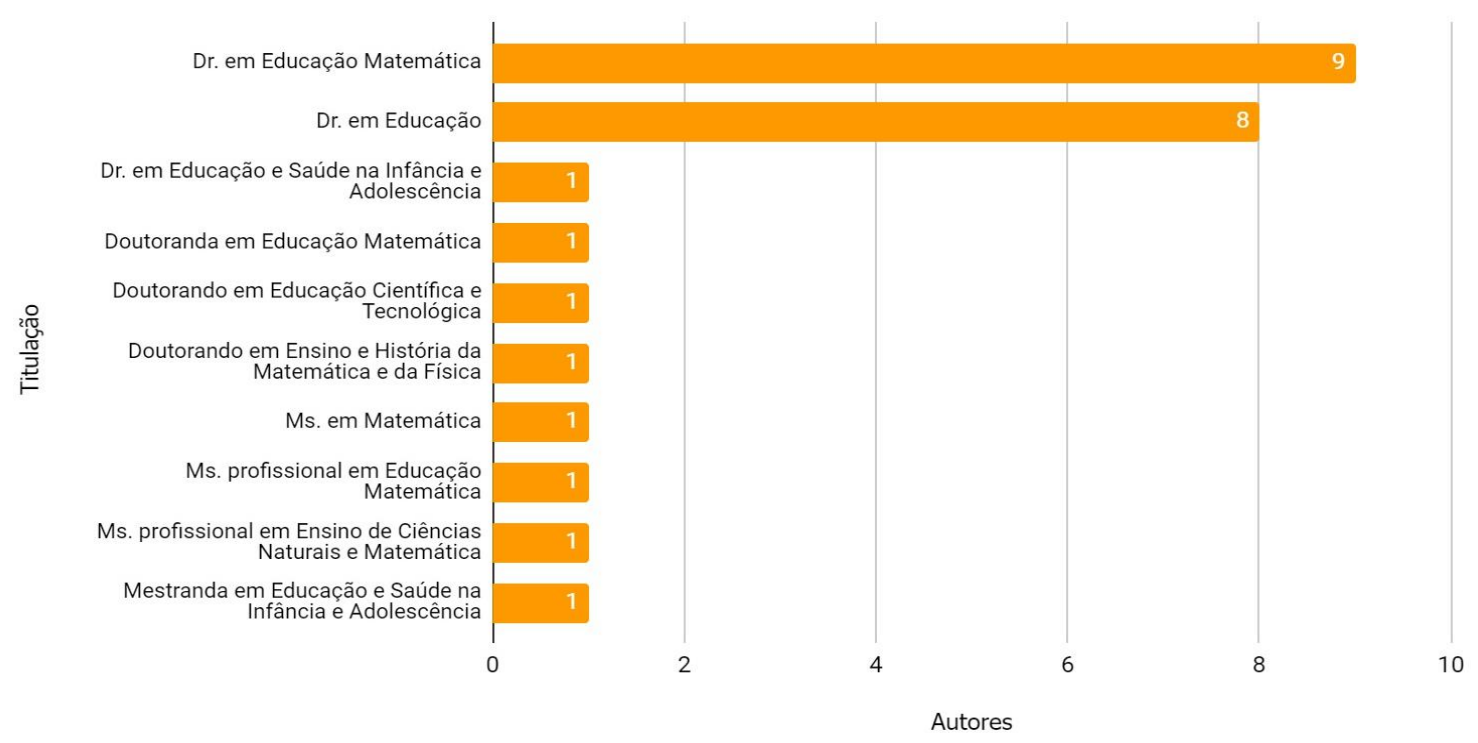

Fonte: Dados da Pesquisa

Compreendemos que os trabalhos do GT15 não representam todo o universo da produção científica da Hem, porém podem ser utilizados como um indicador interessante, para 
identificar as instituições, e os GP's presentes. Além de possibilitar a análise de quais são as temáticas predominantes nos trabalhos e quais os referenciais teóricos e metodológicos mobilizados.

\section{Análise do corpus textual: temáticas, referenciais e metodologias dos trabalhos}

Para a realização do estudo dos dados, optamos pela análise textual, que utiliza desde material transcrito a textos produzidos em diferentes condições, como entrevistas, documentos, entre outros. "Pode ser utilizada a análise textual com a finalidade comparativa, relacional, comparando produções diferentes em função de variáveis específicas que descrevem quem produziu o texto" (Camargo e Justo, 2013, p. 514).

Utilizamos o software IRaMuTeQ (Interface de $\mathrm{R}$ pour les Analyses Multidimensionnelles de Textes et de Questionnaires), que possibilita a realização de análises lexicográficas, identificando a quantidade de palavras e sua frequência média, por exemplo (Camargo e Justo, 2018).

Os dados estatísticos desse corpus textual apresentam as seguintes informações: a) Número de textos - são os textos (registros) contidos no corpus, em nosso caso, por exemplo, o corpus corresponde aos trabalhos do GT15 compostos pelos 17 resumos; b) Número de ocorrências - é o número total de palavras contidas no corpus, correspondente a 2.164 palavras; c) Número de formas - são as palavras consideradas ativas (adjetivos, nomes, verbos) e suplementares (artigos e pronomes). Para a análise foram eliminados os advérbios, as conjunções, onomatopeias e as preposições, que totalizam 665 palavras (Salviati, 2017).

Utilizamos um dos recursos do IRaMuTeQ para visualizar o corpus textual por meio da nuvem de palavras (Figura 1), em razão de agrupar e organizar as palavras pela frequência. As palavras com alta frequência são as maiores e são colocados ao centro, as menores representam frequências inferiores (Camargo e Justo, 2018). 
Figura 1 - Nuvem de palavras corpus textual GT15

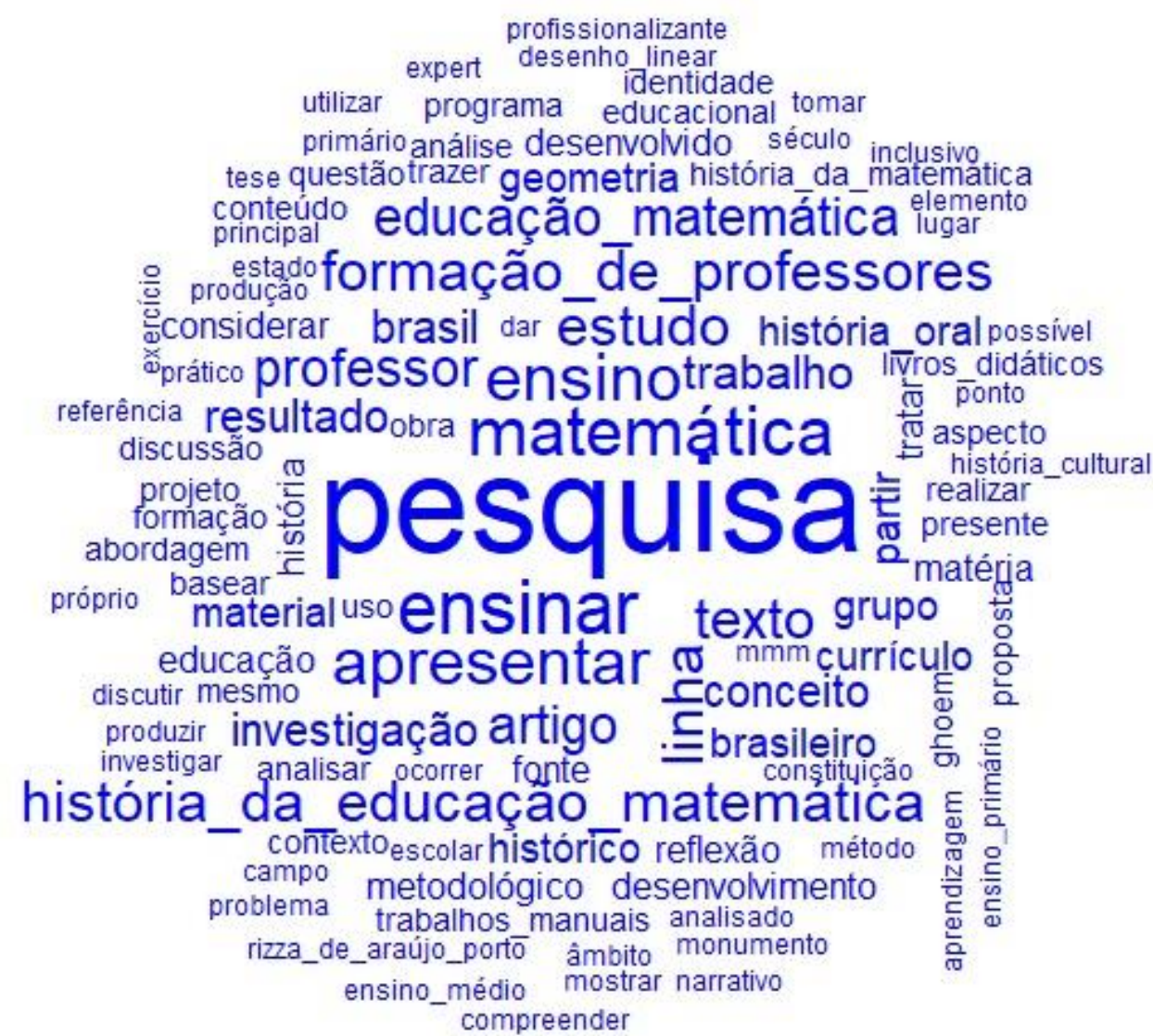

Fonte: Elaboração Própria

Baseado na Figura 1, podemos observar a centralidade da palavra "pesquisa" (citado 28 vezes), esse resultado se dá pelas propostas apresentadas no GT15 que estão relacionados as pesquisas em andamento e concluídas. Outras palavras que indicam temáticas e linhas de pesquisas são: ensinar (frequência 14); matemática (frequência 13); ensino (frequência 12); história da educação matemática, formação de professores e estudo (frequência 10); professor e educação matemática (frequência 9).

Essas palavras mais frequentes nos mostram um indicativo das temáticas como, por exemplo, ensino de matemática, formação de professores e o próprio campo da história da educação matemática. De acordo com os coordenadores do GT15:

A apresentação e discussão dos trabalhos evidenciou as diferentes bases teóricas e metodológicas utilizadas pelos pesquisadores da História da educação matemática oportunizando refletir e questionar potencialidades e limitações de cada uma delas. História Cultural, História Oral, Perspectiva socio-histórica foram algumas das referências mobilizadas pelos autores em seus trabalhos. Outra questão discutida 
pelo grupo foi a participação da matemática em termos de saberes, conteúdos, práticas nas pesquisas em História da educação matemática. Um dos campos de atuação importante dos membros do GT relativamente à Educação Matemática na sua relação com os diferentes níveis educativos tem sido a inserção da História da educação matemática na formação de professores que ensinam matemática. Em atividades disciplinares - criação de disciplinas em cursos de licenciatura - ou mesmo em ações como PIBID, TCC, iniciação científica, a História da educação matemática vem se integrando à formação inicial e continuada de professores (Oliveira e Garnica, 2018, p. 159).

Desta maneira, são feitas perguntas a fim de identificar algumas características, tais como: Quais são os pressupostos teóricos mobilizados? Quais as temáticas? Quais referências são utilizadas? Para isso, utilizamos outro recurso do IRaMuTeQ, a análise fatorial de correspondência (AFC), indicada para descrever um grande volume de dados, associando textos com modalidades de uma única variável de caracterização, isto é, elas possibilitam a comparação (contraste) da produção textual destas modalidades (Camargo e Justo, 2018). Segundo Salviati (2017):

Os procedimentos executados nesta análise englobam o cálculo das frequências e os valores de correlação qui-quadrado de cada palavra do corpus, a partir da frequência pré-definida; e a execução da análise fatorial de correspondências (AFC) numa tabela de contingência que cruza as formas ativas e as variáveis (p.39).

Cabe evidenciar que Bourdieu em suas análises também utiliza a AFC, como pode ser observado no seguinte trecho:

Quando se utiliza uma técnica estatística como a análise de correspondências, cria-se um espaço de várias dimensões em que se distribuem, simultaneamente, propriedades e os detentores dessas propriedades, através de uma operação classificatória que permite caracterizar a estrutura dessa distribuição (Bourdieu, 2001b, p. 88).

A Figura 2 é uma representação gráfica da AFC em plano cartesiano, que auxilia na visualização das proximidades e distanciamentos entre os 17 resumos dos trabalhos apresentados no GT15, a partir do vocabulário do corpus textual, onde podemos identificar quatro quadrantes. 
Figura 2 - AFC corpus textual GT15

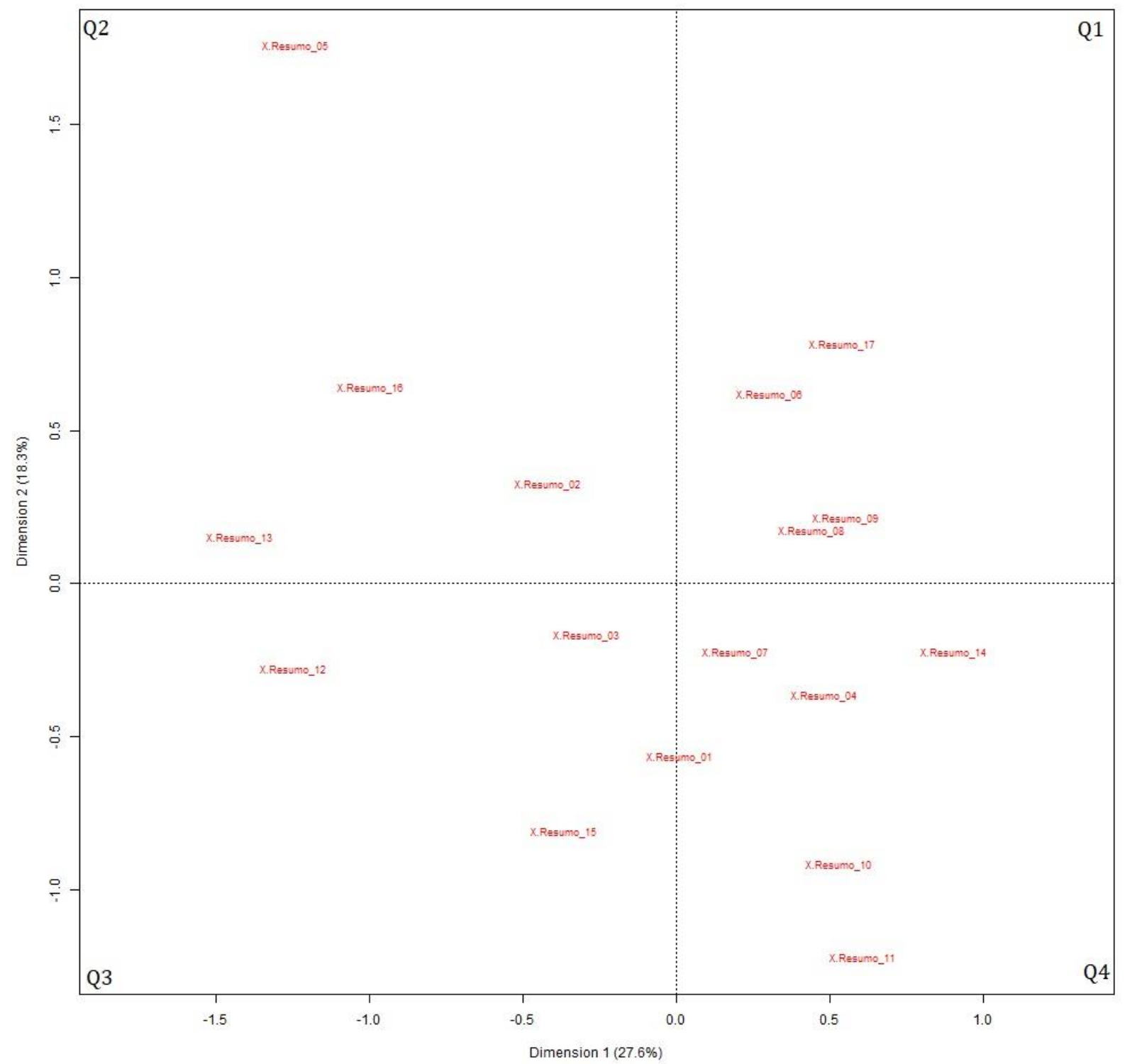

Fonte: Dados da Pesquisa

Podemos observar (Figura 2) que o trabalho que mais se distancia dos demais é o T5, localizado no Q2, cujas autoras analisaram as atividades práticas propostas no âmbito da matéria escolar Trabalhos Manuais que se articulam com a matéria Geometria, assim como a atuação profissional de Olavo Freire da Silva e sua obra Primeiras Noções de Geometria Prática. As análises dos textos permitem identificar que o T5 é o único dos trabalhos que trata da matéria escolar Trabalhos Manuais, e está mais próximo do T16 devido ao conteúdo de Geometria, que é tema de análise dos dois trabalhos.

Outro trabalho que se distancia dos demais é o T11, do grupo de pesquisa GECEM, 
localizado no Q4. As autoras analisam livros didáticos, um conjunto de práticas sócio-culturais, que possibilitam identificar a emergência da educação financeira. As análises dos textos permitem identificar que o T11 é o único dos trabalhos que trata da arqueogenealogia do saber segundo Michel Foucault, razão de seu distanciamento dos demais.

Em relação aos trabalhos que mais se aproximam, podemos observar os trabalhos T8 (Grupo de pesquisa História Oral e Educação Matemática: dos estudos sobre intervenções na formação de professores) e T9 (Grupo de Pesquisa História Oral e Educação Matemática: dos estudos sobre História da Educação Matemática (Inclusiva)), localizados no Q1, cujas autoras evidenciam já no título do trabalho que investigam o grupo de pesquisa GHOEM. Além de realizarem o trabalho baseado no grupo de pesquisa, o caráter que aproxima os trabalhos é a temática investigativa, apresentando as potencialidades da História Oral como uma abordagem pedagógica em processos formativos de professores de Matemática. Assim como, a divulgação das linhas de pesquisas que estão sendo desenvolvidas pelo grupo: História Oral, Narrativas e Formação de Professores: pesquisa e intervenção e Narrativas e ensino e aprendizagem de Matemática (inclusiva).

Outros trabalhos que se aproximam são os T4 e o T14, relativos ao grupo GHOEM, localizados no Q4. O trabalho T4 também apresenta uma linha de pesquisa do grupo e compreende a história oral como metodologia principal, mas não única, do respectivo grupo. Já o trabalho T14 apresenta o referencial metodológico da Hermenêutica de Profundidade, de acordo com John Thompson, mobilizado pelo grupo.

Os trabalhos T3 e T12, localizados no Q3, e o T13 no Q2, possuem as seguintes semelhanças além de serem de pesquisadores do GHEMAT: estão relacionados ao ensino primário e a formação do professor que ensina matemática. Os trabalhos T3 e T13 se assemelham em relação à disciplina de desenho, um dos focos da análise. Ademais, os trabalhos T12 e T13 apresentam, visualmente, uma certa aproximação, cuja análise do texto permitiu identificar que o referencial teórico utilizado em ambos é relacionado aos saberes a ensinar e para ensinar dos autores Rita Hofstetter e Bernard Schneuwly

Com a AFC conseguimos identificar as temáticas dos trabalhos e suas aproximações e distanciamentos. Assim, dando continuidade às análises dos trabalhos, temos como intuito identificar as referências mobilizadas pelos autores dos 17 trabalhos apresentados no VII SIPEM, a fïm de verificar a circulação de conceitos e temáticas desenvolvidas nos trabalhos. 
Segundo Bourdieu (2001b), o que irá contribuir para a legitimação e o reconhecimento do campo científico são as referências e suas citações, isto é:

$\mathrm{Na}$ troca científica, o cientista dá um « contributo » que lhe é reconhecido por actos de reconhecimento público tais como, nomeadamente, a referência como citação das fontes do conhecimento utilizado. Significa que o capital científico é produto do reconhecimento dos concorrentes (um acto de reconhecimento que dá tanto mais capital quanto mais reconhecido é aquele que o realiza, portanto, mais autônomo e mais dotado de capital) (p. 80).

Destarte, é relevante mencionar algumas pesquisas que utilizaram o referencial teórico e metodológico, as referências e citações, como objeto de estudos, a fim de identificar os coletivos de pensamento (CP) e seus estilos de pensamento (EP), ou seja, as práticas, ideias e teorias compartilhadas, de acordo com a epistemologia de Fleck.

[...] a exemplo de Slongo e Delizoicov (2010) que analisando teses e dissertações caracterizaram EPs originários da pesquisa em Ensino de Biologia, de Lorenzetti (2008), que de modo semelhante caracterizou EPs encontrados na pesquisa em Educação Ambiental e Da Ros (2000) que ao analisar teses e dissertações em programas de pós graduação em Saúde Pública pode caracterizar os EPs que constituem essa área (Hoffmann et al., 2019, p. 1073).

Para construção da rede de referências utilizamos o software Gephi, um programa de código aberto para gráficos e análise de rede, que traz novas possibilidades para trabalhar com conjuntos de dados complexos e produzir resultados visuais valiosos. O Gephi foi usado com sucesso para estudos de caso de rede de internet e semântica (Bastian et al., 2009).

Outro trabalho que mobiliza a epistemologia fleckiana, assim como a análise de redes sociais com o auxílio do Gephi, é a pesquisa de Cecco et al. (2017). As autoras analisam os artigos que tratam a respeito da formação de professores que ensinam matemática, em particular os publicados na Revista Bolema (Boletim de Educação Matemática), no período de 1985 a 2015. Dessa forma, construíram uma rede social e intelectual no Gephi, com os 232 autores identificados nos 134 artigos. Analisaram o conhecimento produzido coletivamente, de forma que os pesquisadores ao compartilharem um problema, referencial teórico e práticas comuns formam um coletivo de pensamento.

Em relação aos 17 trabalhos do GT15, foi possível construir uma rede de referências compartilhadas, conforme a Figura 3. Na figura, os nós (as circunferências) representam os trabalhos (T1, T2, T3, .., T16 e T17) e as referências utilizadas com frequência igual ou 
superior a dois. As conexões, ou seja, as arestas, representam a ligação dos trabalhos com as referências. A cor azul representa os trabalhos relacionados ao GHEMAT, em verde os trabalhos do GHOEM, em cor laranja os trabalhos do grupo HIFEM e, em lilás, tem-se trabalhos de três grupos de pesquisa distintos: o T10 do grupo CHATER, o T11 do GECEM e o T15 do grupo HIFOPEM.

Figura 3 - Rede das referências utilizadas nos trabalhos do GT15

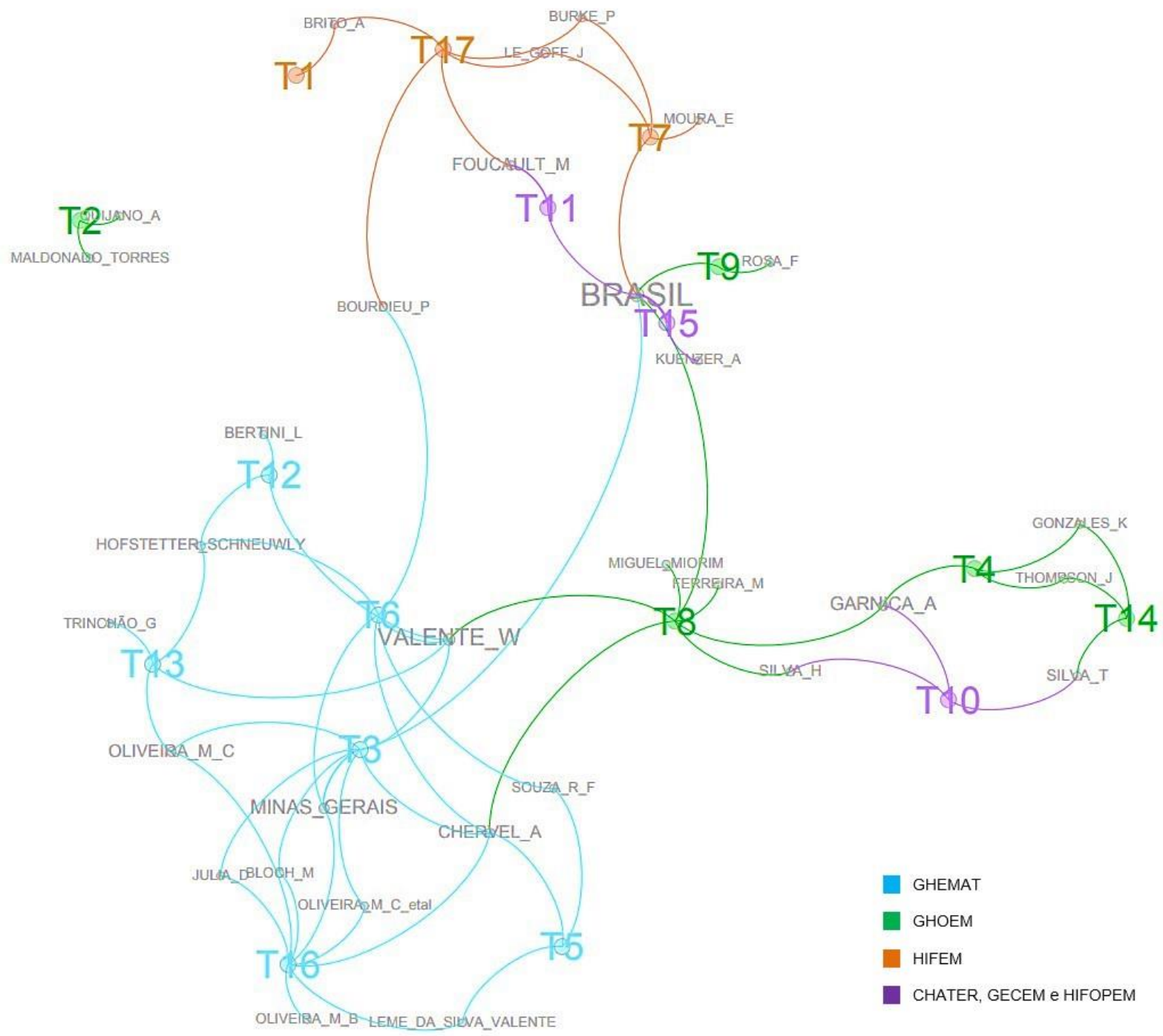

Fonte: Elaboração Própria

Desse modo, as referências mais citadas são os documentos normativos do Brasil (Parâmetros Curriculares Nacionais (PCNs), Base Nacional Curricular Comum (BNCC), declarações, decretos e leis), totalizando 16 correspondências relacionados aos seguintes grupos 
e trabalhos: GHEMAT (T3), GHOEM (T8 e T9), HIFEM (T7), GECEM (T11) e HIFOPEM (T15).

Podemos notar que as referências relacionadas às pesquisas, a contextualização e a constituição do campo científico da Hem e a formação de seus professores, são dos pesquisadores Wagner Rodrigues Valente e Antonio Vicente Marafioti Garnica. Os textos referenciados de Valente totalizam 10 correspondências relacionadas aos trabalhos do GHEMAT (T3, T6, T12, T13) e do GHOEM (T8). Os artigos e/ou livros referenciados podem ser vistos no Quadro 2.

Quadro 2 - Referências mobilizadas do autor Valente.

\begin{tabular}{|c|l|}
\hline Trabalhos GT15 & Título do artigo/livro \\
\hline T3 e T13 & - A matemática nos primeiros anos escolares, elementos ou rudimentos? (2016) \\
\hline T3 & $\begin{array}{l}\text { Oito temas sobre História da Educação Matemática (2013) } \\
\text { - Sobre a investigação dos saberes profissionais do professor de Matemática, algumas } \\
\text { reflexões para a pesquisa (2016) }\end{array}$ \\
\hline T6 & $\begin{array}{c}\text { História da Educação Matemática nos anos iniciais: a passagem do simples/complexo } \\
\text { para o fácil/difícil (2015) } \\
\text { - Matemática no Curso Primário: quando o nacional é internacional, França e Brasil (1880 } \\
\text { a 1960) (2017) }\end{array}$ \\
\hline T8 & $\begin{array}{c}\text { Uma história da matemática escolar no Brasil, 1730-1930 (1999) } \\
\text { do professor de matemática (2010) } \\
\text { - História da Educação Matemática no Brasil (2014) }\end{array}$ \\
\hline T12 & $\begin{array}{c}\text { A Matemática para o Professor dos Primeiros Anos Escolares, a Álgebra Entre a Cultura } \\
\text { Enciclopédica e a Formação Profissional. (2017) }\end{array}$ \\
\hline
\end{tabular}

Fonte: Dados da Pesquisa

Os textos referenciados de Garnica totalizam seis ocorrências e estão relacionados aos trabalhos do GHOEM (T4 e T8) e do grupo CHATER (T10). Nestas mobilizações das referências do autor citado (Quadro 3), observamos que os trabalhos estão relacionados às pesquisas na Hem e em relação aos referenciais e a metodologia da História Oral.

Quadro 3 - Referências mobilizadas do autor Garnica.

\begin{tabular}{|c|l|}
\hline Trabalhos GT15 & \multicolumn{1}{c|}{ Título do artigo/livro } \\
\hline T4 & $\begin{array}{l}\text { A experiência do labirinto, metodologia, história oral e Educação Matemática (2008) } \\
\text { - Sobre a formação de professores de Matemática (2000) } \\
\text { - Fascínio da Técnica, Declínio da Crítica: um estudo sobre a prova rigorosa na formação } \\
\text { de professores de Matemática (1995) }\end{array}$ \\
\hline T8 & $\begin{array}{l}\text { História oral e educação matemática: um inventário (2006) } \\
\text { - Pesquisa em História da Educação Matemática no Brasil - sob o signo da pluralidade } \\
(2016)\end{array}$ \\
\hline T10 & $\begin{array}{l}\text { História oral em educação matemática: um panorama sobre pressupostos e exercícios de } \\
\text { pesquisa (2015) }\end{array}$ \\
\hline
\end{tabular}

Fonte: Dados da Pesquisa

Outras mobilizações importantes são referentes aos estudos do campo da História, com a citação da obra História das disciplinas escolares, reflexões sobre um campo de pesquisa, de 
André Chervel (1990), com cinco correspondências, relacionados às pesquisas do GHEMAT com quatro trabalhos (T3, T5, T6 e T16), e com um trabalho do GHOEM (T8). Do mesmo modo, com as referências mobilizadas pelo grupo HIFEM (T7 e T17) em relação à obra História e Memória de Jacques Le Goff (1992) e de Peter Burke: Variedades de História Cultural (2000), presente no trabalho T7; e A escrita da história: novas perspectivas (2011), no trabalho T17. Outros historiadores citados foram Marc Bloch com Apologia da História, ou O Ofício do Historiador (2002), e Dominique Julia com A cultura escolar como objeto histórico (2001), referenciados, respectivamente, nos trabalhos T3 e T16 do grupo de pesquisa GHEMAT.

O campo científico Filosófico também referenciado, essencialmente pelas obras do autor Michel Foucault, com cinco correspondências, relacionados aos trabalhos do GECEM (T11) com as obras: Ditos e escritos IV (2006), As palavras e as coisas: uma arqueologia das ciências humanas (2007), A verdade e as formas jurídicas (2009) e A Arqueologia do Saber (2017); e as citações do HIFEM (T17) com a obra Vigiar e Punir: nascimento da prisão (1987).

Os temas relacionados ao campo da Sociologia, são as obras de Pierre Bourdieu, Os usos sociais da ciência: por uma sociologia clínica do campo científico (2004), no trabalho T6 do grupo de pesquisa GHEMAT, e Sociologia (1983) referenciado pelo trabalho T17 do grupo HIFEM. Bem como, John Thompson com a obra Ideologia e Cultura Moderna: teoria social crítica na era dos meios de comunicação de massa (1995), citada pelo grupo de pesquisa GHOEM, nos trabalhos T4 e T14.

Segundo Fleck (2010), “podemos dizer, portanto, que qualquer tráfego intercoletivo de pensamentos traz consigo um deslocamento ou uma alteração dos valores de pensamento" (p. 161). Assim, a produção analisada se objetiva na seguinte maneira, "começa com a referência a outros pesquisadores e ao percurso histórico de um problema, para despersonalizá-lo; introduz nomes específicos: 'termos técnicos'; acrescentam-se signos particulares e, eventualmente, toda uma linguagem particular de signos" (p. 200). Mesmo que os trabalhos apresentados tenham sido desenvolvidos por indivíduos isolados, é possível perceber, principalmente por meio dos referenciais teóricos que compartilham, certo nível de congruência entre esse conjunto de trabalhos, os quais apresentaram um diálogo com diferentes campos científicos, como da História, da Filosofia e da Sociologia, para produzir estudos no campo da Hem no Brasil. 


\section{Algumas considerações}

Nosso objetivo neste artigo foi analisar os trabalhos apresentados no VII Seminário Internacional de Pesquisa em Educação Matemática (SIPEM), em particular o Grupo de Trabalhos (GT) número 15, intitulado História da educação matemática, realizado no ano de 2018. Assim, houve perguntas que nortearam nossa investigação.

A primeira é relacionada a identificação dos grupos de pesquisas (GP's). Podemos observar que os GP's mais presentes, dentro deste universo, são o GHEMAT, com seis trabalhos apresentados e o GHOEM, com cinco trabalhos. A identificação dos GP's pode ser um fator relevante para caracterizar as diferentes temáticas dos trabalhos, assim como, a participação de um pesquisador em mais de um grupo pode apresentar uma circulação de ideias, práticas e teorias.

Os resultados das análises mostraram que as temáticas que estão sendo tratadas e as metodologias, há uma aproximação dos temas de acordo com as temáticas dos próprios GP's. Ou seja, os trabalhos relacionados ao GHOEM, dentro das diferentes linhas de pesquisa do grupo, tiveram como objetivo apresentar as pesquisas e as potencialidades da História Oral como uma abordagem pedagógica em processos formativos de professores de Matemática.

Em relação aos trabalhos relacionados ao GHEMAT, observamos que possuem temáticas com referências teóricos comuns, ou seja, há uma circulação do referencial teórico e metodológico no grupo. Porém, pela análise textual, os objetos de estudo se diferem quanto aos conteúdos da matemática, como, por exemplo, trabalhos manuais, desenho, geometria, resolução de problemas, entre outros. No entanto, os trabalhos se aproximam quanto às análises que investigam a formação de professores, a matemática escolar, e os documentos normativos mobilizados de um determinado período, como programas de ensino, livros didáticos, revistas pedagógicas, entre outras fontes documentais.

Outra observação está relacionada a produção do conhecimento fortemente ligada aos projetos de pesquisas dos grupos e à pós-graduação, sendo que a maioria dos trabalhos apresentados é oriunda da região sudeste, de instituições como a UNESP e a UNIFESP. Outro aspecto que destacamos é a formação, em particular a especialização desses pesquisadores que investigam a Hem, que em sua maioria são do campo científico da Educação e da Educação Matemática, espaços que já possuem reconhecimento e legitimação dentro do campo, assim como, pelos pares e pelos seus concorrentes. 
A rede de referências compartilhadas apresentou diálogos com diferentes campos de pesquisas e os usos de referenciais comuns, como, por exemplo, com os campos científicos da História, Filosofia, Sociologia e em relação às pesquisas que tratam da constituição do próprio campo da Hem, com os trabalhos dos pesquisadores Antonio Vicente Marafioti Garnica e Wagner Rodrigues Valente. Assim, inferir a respeito de um ou mais coletivos de pensamento, de acordo com a epistemologia de Fleck, "é o resultado sócio-histórico de um coletivo e está vinculado a fatores sócio-culturais, empíricos e lógicos" (Hoffmann et al., 2019, p. 1070).

Contudo, identificamos coletivos de pesquisadores que possuem temáticas similares e mobilizam autores de campos científicos reconhecidos e autônomos. Finalizamos com uma frase de Bourdieu (2001b), "a objectividade é um produto intersubjectivo do campo científico: fundada nos pressupostos partilhados nesse campo, é resultado do acordo intersubjectivo no campo" (p. 115).

\section{Referências}

Bastian, M., Heymann, S., e Jacomy, M. (2016). Gephi, an open source graph visualization and manipulation software.[s.l: s.n.].

Bellemain, F. e Gitirana, V. (2012). Anais V SIPEM. Seminário Internacional de Pesquisa em Educação Matemática, Petrópolis, Rio de Janeiro, 28 a 31 de outubro de 2012.

Bicudo, M. A. V e Miarka, R. (2015). Metodologia de Pesquisa em Filosofia da Educação Matemática. Perspectivas da Educação Matemática, Campo Grande - MS, 8(18), 5.

Bicudo, M. A. V. e Kluber, T. E. (2011). Pesquisa em Modelagem Matemática no Brasil: a caminho de uma metacompreensão. Cad. Pesqui., São Paulo, 41(144), 904-927.

Bicudo, M. A. V. e Paulo, R. M. (2011). Um Exercício Filosófico sobre a Pesquisa em Educação Matemática no Brasil. Bolema, Rio Claro, 25(41), 251-298.

Bourdieu, P. (2001a). Meditações pascalianas. Rio de Janeiro: Bertrand Brasil.

Bourdieu, P. (2001b). Para uma sociologia da ciência. Lisboa: Ed. 70.

Camargo, B. V. e Justo, A. M. (2013). IRAMUTEQ: um software gratuito para análise de dados textuais. Temas em Psicologia, 21(2), 513-518.

Camargo, B. V. e Justo, A. M.(2018). IRAMUTEQ: Tutorial para uso do software de análise textual IRAMUTEQ. Florianópolis: Laboratório de Psicologia Social da Comunicação e Cognição- LACCOS, Universidade Federal de Santa Catarina, Brasil.

Campos, T. M. M. e Pires, C. M. C. (2000). Anais I SIPEM. Seminário Internacional de Pesquisa em Educação Matemática, Serra Negra, São Paulo, 22 a 25 de novembro.

Carneiro, R. F. (2018). Anais VII SIPEM. Seminário Internacional de Pesquisa em Educação Matemática, Foz do Iguaçu, Paraná, 4 a 8 de novembro. 
Cecco, B. L., Bernardi, L. T. M. S. e Delizoicov, N. C. (2017). Formação de Professores que Ensinam Matemática: um olhar sobre as redes sociais e intelectuais do BOLEMA. Bolema, Rio Claro, 31(59), 1101-1122.

Coppe, C., Flores, C. R., Orey, D. C. e Oliveira, M. C. A. (2018). History of Mathematics and Culture: Moments and Movements in Brazilian Mathematics Education. In: Ribeiro, A. J., Healy, L., Borba, R. E. S. R. e Fernandes, S. H. A. A. (Org.). Mathematics Education in Brazil Panorama of Current Research. 1ed.Switzerland: Springer, v. 1, 2018. p. 1-278.

Dos Anjos, D. Z. e Moretti, M. T. (2017). Ensino e Aprendizagem em Matemática para Estudantes Cegos: Pesquisas, Resultados e Perspectivas. Jornal Internacional de Estudos em Educação Matemática, 10(1), p. 15-22.

Fernandes, S. H. A. A. (2015). Anais VI SIPEM. Seminário Internacional de Pesquisa em Educação Matemática, Pirenópolis, Goiás, 15 a 19 de novembro.

Fleck, L. (2010). Gênese e Desenvolvimento de um Fato Científico: introdução à doutrina do estilo de pensamento e do coletivo de pensamento. Belo Horizonte, Fabrefactum Editora.

Furinghetti, F. e Karp, A. (Org.). (2018). Researching the History of Mathematics Education: ICME-13 Monographs. 1ed.Cham: Springer International Publishing, 2018. Disponível em: <https://doi.org/10.1007/978-3-319-68294-5>. Acesso em: 26 nov. 2018.

Garnica, A. V. M., Soares, M. T. C. e Buriasco, R. L. C. (2006). Anais III SIPEM. Seminário Internacional de Pesquisa em Educação Matemática, Águas de Lindóia, São Paulo, 10 a 14 de outubro.

González, F.E. (2018). Historia de la Educación Matemática en Latinoamérica: 10 claves para su comprensión. Unión: revista iberoamericana de educación matemática, 58, abr. 2018, 279-305. Disponível em: http://www.fisem.org/www/union/revistas/2018/52/historia.pdf

Hoffmann, Y. T., Costa, D. A. da, Nakamura, L. R. e Delizoicov Neto, D. (2019). Circulação inter e intracoletiva em Grupos de Pesquisa de História da Educação Matemática. Ciência \& Educação (Bauru), 25(4), 1067-1080. Epub December 20, 2019. https://doi.org/10.1590/1516-731320190040014

Kluber, T. E. e Burak, D. (2012). Sobre a Pesquisa Qualitativa na Modelagem Matemática em Educação Matemática. Bolema, Rio Claro, 26(43), 883-905, Aug.

Kluber, T. E. e Burak, D. (2014). Sobre a pesquisa em Modelagem na Educação Matemática brasileira. Revista Diálogo Educacional, [S.1.],14(41), 143-163, jul.

Matos, J. M. e Saraiva, M. (2011). Congresso Ibero-americano de História de Educação Matemática (1.: 2011: Covilhã: Portugal). Anais do I Congresso Ibero-americano de História da Educação Matemática.

Miguel, A., Garnica, A. V. M., Igliori, S. B. C., e D'Ambrósio, U. (2004). A educação matemática: breve histórico, ações implementadas e questões sobre sua disciplinarização. Revista Brasileira de Educação, (27), 70-93.

Mocrosky, L. F., Paulo, R. M. e Bicudo, M. A. V. (2010). A avaliação em Educação Matemática: um olhar fenomenológico sobre a produção acadêmica do III SIPEM. Revista Brasileira de Ensino de Ciência e Tecnologia, 3(2), mai./ago. 
Oliveira, M. C. A e Garnica, A. V. M. (2018). Relatório do GT 15 - História da educação matemática. In: Relatório VII SIPEM. Seminário Internacional de Pesquisa em Educação Matemática, Foz do Iguaçu, Paraná, 4 a 8 de novembro de 2018, 155-164.

Oliveira, W. P. e Kluber, T. E. (2017). Formação de professores em Modelagem Matemática: uma hermenêutica dos relatórios do GT 10 - Modelagem Matemática da SBEM. Educação Matemática Pesquisa: Revista do Programa de Estudos Pós-Graduados em Educação Matemática, [S.1.], 19(2), set.

Pinto, N. B. (2014). A Educação Matemática Brasileira e a Realização do Primeiro Encontro Nacional de Pesquisas em História da Educação Matemática. Da importância do I ENAPHEM. In: Valente, W. R. (Org.). História da Educação Matemática no Brasil. Problemáticas de pesquisa, fontes, referências teórico-metodológicas e histórias elaboradas. 1ed.São Paulo: Editora Livraria da Física, 2014, 13-29.

Salviati, M. E. (2017). Manual do Aplicativo Iramuteq (versão 0.7 Alpha 2 e R Versão 3.2.3). Compilação, organização e notas de Maria Elisabeth Salviati. 2017. Disponível $\mathrm{em}:<$ http://iramuteq.org/documentation/fichiers/manual-do-aplicativo-iramuteq-par-mariaelisabeth-salviati> . Acesso em: 10 nov. 2018.

Santos, M.C. e Lima, P. F. (2009). Anais IV SIPEM. Seminário Internacional de Pesquisa em Educação Matemática, Brasília, Distrito Federal, 25 a 28 de outubro.

Valente, W. R. (2013). Anais II SIPEM. Seminário Internacional de Pesquisa em Educação Matemática, Santos, São Paulo, 29 de outubro a 01 de novembro.

\section{AGRADECIMENTOS}

Os autores agradecem o apoio desta pesquisa dado pelas seguintes agências de fomento:

1. Coordenação de Aperfeiçoamento de Pessoal de Nível Superior (CAPES)

2. Fundação de Amparo à Pesquisa e Inovação do Estado de Santa Catarina (FAPESC) 